\title{
A RELAÇÃO ENTRE INVESTIMENTOS SOCIOAMBIENTAIS E DESEMPENHO FINANCEIRO: EVIDÊNCIAS DO SETOR ENERGÉTICO BRASILEIRO
}

\author{
${ }^{1}$ Joaes dos Santos Oliveira Mota \\ ${ }^{2}$ Márcio Sampaio Pimentel
}

\section{RESUMO}

Este estudo objetivou analisar a relação entre os investimentos em práticas socioambientais e o desempenho financeiro das empresas de capital aberto listadas na Bovespa, pertencentes ao segmento de energia elétrica que publicaram seus Relatórios Socioambientais entre os anos de 2015 e 2019. A metodologia aplicada é de natureza descritiva, documental e quantitativa. Os dados socioambientais foram obtidos por meio da análise dos relatórios socioambientais, especificadamente no Balanço Ibase, enquanto os dados financeiros foram coletados no site da Bovespa. Para a amostra, com 14 empresas, foram aplicadas técnicas de análise estatística dos dados, como estatística descritiva, correlação e regressão com dados em painel. Os resultados evidenciaram que os investimentos em ISI foram os mais expressivos em termos de valores. Observou-se correlação negativa e significativa entre as variáveis ISI e ROA e positiva e significativa entre ROE e ROA, sendo que a primeira correlação indica, a priori, que, quanto menor for o valor do retorno dos ativos das empresas, maior será os investimentos sociais internos. Quanto aos resultados da análise de regressão, os indicadores ROA e ROE obtiveram achados estatisticamente iguais em relação aos investimentos socioambientais e o porte das companhias, com exceção da variável ISI, a qual indicou que o investimento nos colaboradores gerou retorno positivo e significativo para os acionistas da empresa, o que não foi observado para o retorno dos ativos, que teve relação negativa e significante.

Palavras-chave: Responsabilidade Socioambiental. Indicadores Socioambientais. Desempenho Financeiro. Setor de Energia Elétrica.

\section{RELATIONSHIP BETWEEN SOCIAL AND ENVIRONMENTAL INVESTMENTS AND FINANCIAL PERFORMANCE: EVIDENCE FROM THE BRAZILIAN ENERGY SECTOR}

\begin{abstract}
This study aimed to analyze the relationship between investments in social and environmental practices and the financial performance of publicly traded companies listed on Bovespa, belonging to the electricity sector that published their Social and Environmental Reports between 2015 and 2019. The methodology applied is a specific descriptive, documentary, and quantitative. Social and environmental data were obtained by analyzing social and environmental reports, specifically on the Ibase Balance Sheet, while financial data were collected on the Bovespa website. For the sample of 14 companies, statistical data analysis techniques were applied, such as descriptive statistics, correlation, and regression with panel data. The results showed that investments in ISI were the most expressive in terms of values. There was a negative and significant correlation between the variables ISI and ROA and a positive and significant correlation between ROE and ROA, with the first correlation indicating, a priori, that the lower the return on company assets, the greater the internal social investments. As for the results of the regression analysis, the ROA and ROE indicators obtained statistically similar findings concerning socio-environmental investments and the size of the companies, except for the variable ISI, which indicated that the investment in employees generated a positive and significant return for shareholders of the company, which was not observed for the return on assets, which had a negative and significant relationship.
\end{abstract}

Key words: Social and Environmental Responsibility. Social and Environmental Indicators. Financial Performance. Electric Power Sector.

\footnotetext{
${ }^{1}$ Universidade Federal Rural de Pernambuco - UFRPE, Pernambuco, (Brasil). https://orcid.org/0000-0002-8959-5666

E-mail: joaesmota@gmail.com

${ }^{2}$ Universidade Federal Rural de Pernambuco - UFRPE, Pernambuco, (Brasil). https://orcid.org/0000-0003-0380-2554

E-mail: marcio.pimentel@ufrpe.br
} 


\section{INTRODUÇÃO}

A incorporação de práticas sustentáveis tem crescido no ambiente empresarial desde a formulação do conceito de sustentabilidade corporativa, tendo como base o Triple Bottom Line definido por Elkington (1994), independente do porte das empresas, desde pequenas a grandes corporações. A sustentabilidade pode ser vista como um compromisso que busca permitir a uma empresa desenvolver novas alternativas que sejam sustentáveis, visando assim alcançar novas perspectivas, tais como o desenvolvimento socioambiental, ao invés de focar somente em ganhos econômicos (Jaber, 2020).

Na visão de Cohen et al. (2017), uma empresa é tida como sustentável quando a consecução de suas ações leva em conta os aspectos econômicos, sociais e ambientais, ou seja, a empresa visa ao lucro, mas se esforça para minimizar o impacto de seu comportamento no meio ambiente de forma eficiente e realiza ações sociais para a comunidade, por meio da Responsabilidade Ambiental e Responsabilidade Social, respectivamente.

Ante a isso, os serviços descritos como de utilidade pública, tais como o fornecimento de energia elétrica, são descritos como fundamentais para o desenvolvimento dos países, seja em aspectos econômicos, financeiros, ambientais e sociais. Neste cenário, "o setor de energia elétrica é dividido em três segmentos (geração, transmissão e distribuição), cuja exploração ocorre por empresas de capital público e/ou privado" (Ribeiro et al., 2017, p. 44), sendo basicamente formado pela geração hidráulica (Leing et al., 2014). Tolmasquim (2016) destaca que o setor brasileiro, no que se refere à capacidade energética, detém cerca de $10 \%$ do potencial hidráulico mundial, enfatizando ainda que o setor tem buscado sistematicamente atuar e planejar levando em consideração aspectos socioambientais.

Há na literatura diversos estudos que investigam a relação entre os investimentos socioambientais e o desempenho financeiro: internacionais (Saleh et al., 2011; Partalidou, 2020), nas empresas brasileiras listadas na B3 (Tupy, 2008; Campos, 2011; Orellano \& Quiota, 2011; Círico Junior \& Galvão, 2020; Cruz et al., 2020), em pequenas e médias empresas (Paiva et al., 2019) e específicos do segmento de energia elétrica (Lima et al., 2013; Fasolin et al., 2014; Ribeiro et al., 2017; Goulart \& Ferreira, 2019). Os resultados de tais estudos são ainda heterogêneos e divergentes, surgindo assim uma lacuna a ser investigada.

Nesse contexto, uma vez que as empresas de energia elétrica operam em um ambiente altamente competitivo e com fortes impactos econômicos, ambientais e sociais, passam, então, a desempenhar um papel fundamental nos fatores de responsabilidade socioambiental (Ribeiro et al., 2017) e, em decorrência da lacuna existente quanto aos resultados dos estudos empíricos acerca da relação entre os investimentos socioambientais e o desempenho financeiro, emerge a seguinte questão de pesquisa: Qual a relação entre os investimentos em práticas socioambientais e o desempenho financeiro das empresas do segmento de energia elétrica listadas na Bovespa?

Em síntese, esta pesquisa objetiva analisar a relação entre os indicadores socioambientais e o desempenho financeiro em companhias de capital aberto do segmento de energia elétrica que compõe o Índice Bovespa, no período de 2015 a 2019, examinando tal relação em um período de pós-obrigatoriedade da elaboração do Relatório de Responsabilidade Socioambiental por este segmento. Para tanto, foi organizado um banco de dados com empresas do segmento de energia elétrica que publicaram seus Relatórios Socioambientais entre os anos de 2015 e 2019 e que sejam de capital aberto e listadas em algum segmento de Governança Corporativa da Bovespa.

Assim, este estudo se justifica ao abordar um setor de fundamental importância para o Brasil, no contexto social e ambiental, se conjecturando em um dos principais objetivos definidos na Agenda 2030 para o Desenvolvimento Sustentável (Objetivo 7), pela Organização das Nações Unidas (ONU), bem como por ajudar a preencher a lacuna existente entre os investimentos socioambientais e o retorno financeiro das empresas e por considerar um setor representativo do Índice Bovespa - o de energia elétrica. 
Este estudo divide-se em cinco partes, incluindo esta introdução. A segunda parte apresenta o referencial teórico, a terceira parte a descrição dos aspectos metodológicos, na quarta parte discute-se a apresentação e análise dos resultados e, finalmente, na última parte, destacam-se algumas considerações finais.

\section{RESPONSABILIDADE SOCIOAMBIENTAL}

A Responsabilidade Social Corporativa (RSC) é vista como "um compromisso contínuo das empresas para agir de forma ética e contribuir para o desenvolvimento econômico enquanto melhora a qualidade de vida da sua força de trabalho e suas famílias, bem como da comunidade local e da sociedade como um todo" (Holme \& Watts, 2000, p. 8). Carroll (1979), em um dos seus estudos seminais acerca do tema responsabilidade social dos negócios, aduz que esse abrange os aspectos econômicos, éticos, jurídicos e discricionários relativos à atenção que é dada por uma empresa às expectativas que as partes interessadas (stakeholders) possuem em um determinado contexto.

A Global Reporting Iniciative (2012) descreve que a RSC pode ser entendida como uma licença social de operação da sociedade, enfatizando que, para uma organização englobar aspectos econômicos, sociais e ambientais em suas operações ou até divulgá-las de forma confiável e coerente, requer um alto custo nos dias atuais. Ainda, em termo conceitual, o Instituto Ethos (2012) preceitua que a RSC

é a forma de gestão que se define pela relação ética e transparente da empresa com todos os públicos com os quais ela se relaciona e pelo estabelecimento de metas empresarias que impulsionem o desenvolvimento sustentável da sociedade, preservando recursos ambientais e culturais para as gerações futuras, respeitando a diversidade e promovendo a redução das desigualdades sociais (INSTITUTO ETHOS, 2012).

Sintetizando esses conceitos, Irigaray et al. (2017) comentam que a RSC é um conjunto diverso que circunda iniciativas sociais e ambientais discricionárias, pois podem envolver aspectos de assistencialismo aos fornecedores que por ventura adotem práticas sustentáveis, ecológicas e sociais, ações que foquem no impacto social da empresa em termos de comunidade, assim como por meio da melhoria do bem-estar dos colaboradores da organização.

Conceitua-se que tanto a Responsabilidade Social como a Responsabilidade Ambiental fazem parte da sustentabilidade corporativa, contudo Cohen et al. (2017) aduzem que as organizações as praticam de forma desintegrada, cada uma dentro de um contexto específico. No entanto, nos últimos anos, é perceptível que há uma busca, por parte de algumas empresas, em unificarem em uma mesma área funcional, por meio do termo Sustentabilidade, ou ainda de forma mais comum, Responsabilidade Socioambiental (RSA). Assim sendo, no presente artigo, preconizase que, no contexto da RSC, também estão inclusas questões de cunho ambiental, optando assim pelo uso do termo RSA ao longo do texto, uma vez que se torna mais perceptível os aspectos sociais e ambientais.

O conceito de RSA, para Fatemi et al. (2018), relativa às partes interessadas, envolve as dimensões ambientais e sociais, bem como as de governança. Uma diversidade de estudos e abordagens foram e estão sendo desenvolvidos na busca de explicar o efeito do desempenho da RSA no desempenho financeiro (Partalidou et al., 2020). A despeito desses estudos, a relação entre RSA e desempenho não é, no entanto, inteiramente linear (Barnett \& Salomon, 2006).

Ante a isso, DiSegni et al. (2015) comentam que há estudos que sugerem uma relação negativa entre responsabilidade social e desempenho financeiro, para tanto argumentam que a alta responsabilidade resulta em custos adicionais que colocam a empresa em desvantagem econômica em comparação com outras empresas. No entanto, os referidos autores também citam outros estudos que concluíram que os custos adicionais são potencialmente compensados por uma gama de benefícios diretos e indiretos que, de maneira geral, resulta em uma associação positiva entre 
responsabilidade social e desempenho financeiro. Cita-se, como um desses fatores benéficos, parcialmente mencionado, que a responsabilidade social melhora a boa vontade do funcionário e do cliente como um resultado importante da responsabilidade social, juntamente com a moral e a produtividade do funcionário.

Observa-se que um grande percalço nos estudos que analisam essa relação está na seleção de quais indicadores de desempenho financeiro devem ser utilizados, em alguns estudos fazem uso de indicadores de mercado e/ou outros usam indicadores contábeis (Orellano \& Quiota, 2011). Os referidos autores enfatizam que com relação aos indicadores de mercado, alguns estudos (ver exemplo de Abbott e Monsen (1979) e Cochran e Wood (1984)) fazem uso do "retorno ao investidor como uma medida de desempenho do ponto de vista dos acionistas, enquanto outros autores utilizam a variação do preço das ações, acrescentando os dividendos na composição desse indicador" (Orellano \& Quiota, 2011, p. 473).

No tocante aos indicadores contábeis, o uso maior é de indicadores que buscam refletir o desempenho financeiro como sendo o resultado da administração interna de uma organização. Nos estudos de Orellano e Quiota (2011) e Ribeiro et al. (2017), as variáveis utilizadas, como indicadores contábeis, foram o Retorno sobre Ativos (ROA) e Retorno sobre o Patrimônio Líquido (ROE). No entanto, o retorno sobre as vendas (ROS) também está presente em alguns estudos (Waddock \& Graves, 1997).

Com relação aos indicadores socioambientais, a busca é ainda mais desafiadora, uma vez que um dos principais gargalos para a realização das pesquisas acerca do tema desempenho socioambiental é a falta de dados que permitam evidenciar esse desempenho tanto de forma qualitativa como quantitativa das ações de RSA que as empresas executaram (Orellano \& Quiota, 2011). Buscando sanar esse gargalo, esta pesquisa faz uso do balanço social, ou seja, uma ferramenta de fundamental importância para que as empresas divulguem e demonstrem suas atividades voltadas para programas sociais relativos aos funcionários, à comunidade e ao meio ambiente, além de fazer as prestações de contas anuais relativas a esta temática, corroborando para que ocorra a comprovação de seu desempenho na esfera social (Lima \& Santos, 2019).

Em um contexto mais abrangente, Tinoco (2010) descreve que o balanço social é uma importante ferramenta de gestão e para o processo informacional que busca, de maneira mais clara possível, evidenciar ações sociais, como também ações contábeis, econômicas e ambientais relativas ao desempenho das organizações às diversas partes interessadas. Nesse cenário, o balanço social acabou ganhando cada vez mais importância e com isso algumas entidades propuseram modelos, dentre eles: o Global Reporting Initiative (GRI); Instituto Brasileiro de Análises Sociais e Econômicas (Ibase); e o roteiro do Instituto Ethos. Para este trabalho, será usado o modelo Ibase que, segundo Goulart e Ferreira (2019), é composto por 7 categorias que buscam destacar as ações da organização, são elas: i. econômica, ii. sociais internos, iii. sociais externos, iv. ambientais, v. do corpo funcional, vi. informações relativas ao exercício da cidadania empresarial, que sejam relevantes; e, vii. outras informações que sejam relevantes para a compreensão das práticas sociais e ambientais de uma empresa.

No que concerne aos Indicadores Sociais, esses se dividem em Indicadores Sociais Internos e Externos. Nessa perspectiva, Círico Junior e Galvão (2020) destacam que esses indicadores "referem-se aos investimentos empresariais referentes ao corpo funcional da empresa (Indicadores Internos) e os investimentos relacionados à sociedade (Indicadores Externos), de modo que possa haver desenvolvimento coletivo" (p. 343). No que se refere aos Indicadores Ambientais, Faur et al. (2008) aduzem que esses indicadores destacam a responsabilidade de uma organização em relação ao aspecto ambiental, tais como sobre as ações que buscam evidenciar práticas voltadas para a preservação ambiental, bem como de ações relativas à redução do impacto ambiental.

Destaca-se que, a partir do exercício de 2015, a Agência Nacional de Energia Elétrica (Aneel) tornou obrigatória a elaboração do Relatório de Responsabilidade Socioambiental e Econômico-Financeiro, que inclui o balanço social, por meio do Manual de Contabilidade do Serviço Público de Energia Elétrica (MCSPEE), a todas as outorgadas do setor de energia elétrica, 
tendo como exceção os autoprodutores e os produtores independentes que utilizam totalmente ou parcialmente a energia elétrica como insumo para o seu processo produtivo (Aneel, 2015).

Ressalta-se que fica a critério da empresa elaborar seus relatórios com base em padrões mais abrangentes, como é o caso do modelo atualizado da GRI (Ribeiro et al., 2017), desde que comtemple as dimensões que são apresentadas no modelo proposto pela Aneel. Tais dimensões são: i. Dimensão Geral - informações gerais da empresa; ii. Dimensão Governança Corporativa princípios éticos e transparência, a prestação de contas e os valores que governam a organização; iii. Dimensão Econômico-Financeira - os indicadores econômico-financeiros e os investimentos na concessão; iv. Dimensão Social e Setorial - descrever o desempenho social da Outorgada, como também apresentar temas sociais específicos do setor elétrico; e, v. Dimensão Ambiental - devem ser apresentados os impactos socioambientais gerados pelas atividades da outorgada, as iniciativas para mitigar esses impactos e a extensão da redução desses impactos (Aneel, 2015).

\subsection{Hipóteses}

Tem havido, nos últimos anos, uma crescente busca em neutralizar a ideia que foi amplamente difundida de que uma organização não possui outra obrigação além de maximizar a riqueza dos acionistas. Tal ideia de que existem pessoas e grupos, mais os acionistas, com os quais uma empresa tem obrigações, passou a ser amplamente conhecida como a teoria dos stakeholders (DiSegni et al., 2016). Na relação entre RSA e desempenho financeiro, Saleh et al. (2011) evidenciam que, assim como a teoria dos stakeholders, existem outros três postulados teóricos que buscam explicar essa relação, a saber: a teoria do trade-off; a teoria de oferta e demanda da empresa e a teoria do impacto social.

Tabela 1 - Relação entre RSA e desempenho financeiro

\begin{tabular}{cclcc}
\hline Teoria & Autor & \multicolumn{1}{c}{ Descrição } & Relação \\
\hline $\begin{array}{c}\text { Teoria do trade- } \\
\text { off }\end{array}$ & $\begin{array}{c}\text { Introduzida por } \\
\text { Friedman (1970) }\end{array}$ & $\begin{array}{l}\text { Para essa teoria, a única responsabilidade social da } \\
\text { empresa é aumentar os lucros. Além disso, quando as } \\
\text { empresas se envolvem em atividades sociais e ambientais, } \\
\text { isso incorre em despesas extras e diminui os seus ganhos. }\end{array}$ & Negativa \\
\hline $\begin{array}{c}\text { Teoria da oferta } \\
\text { e demanda da } \\
\text { empresa }\end{array}$ & $\begin{array}{c}\text { Introduzida por } \\
\text { McWilliams e } \\
\text { Siegel (2001) }\end{array}$ & $\begin{array}{l}\text { De acordo com essa teoria, a demanda pelo envolvimento } \\
\text { de uma empresa nas atividades de RSA maximiza os } \\
\text { lucros da empresa. Afirma-se que, em condições de } \\
\text { equilíbrio, o nível de RSA pode ser diferente; contudo, o } \\
\text { lucro pode ser maximizado ou não alterado. }\end{array}$ & \\
\hline $\begin{array}{c}\text { Teoria do } \\
\text { impacto social }\end{array}$ & $\begin{array}{c}\text { Introduzida por } \\
\text { Cornell e Shapiro } \\
\text { (1987) }\end{array}$ & $\begin{array}{l}\text { Assume que a melhoria das atividades de RSA de uma } \\
\text { empresa irá melhorar o desempenho financeiro. Portanto, } \\
\text { os benefícios esperados de realizar atividades de RSA } \\
\text { excederão as despesas de fazê-las. }\end{array}$ & Positiva \\
\hline
\end{tabular}

Fonte: Saleh, Zulkifli e Muhamad (2011).

Dessa forma, constata-se que os resultados da relação entre RSA e desempenho financeiro são divergentes a depender da teoria. Contudo, tanto a Teoria do impacto social como a Teoria dos Stakeholders preceitua que a correlação entre responsabilidade socioambiental e desempenho econômico-financeiro deve ser positiva, uma vez que, quanto maior for a RSA, espera-se que maior seja a eficácia e a eficiência administrativa, ensejando em um melhor desempenho econômicofinanceiro (Paiva et al., 2019). Com base nessa premissa e em consonância com o estudo de Ribeiro et al., 2017, testaram-se as seguintes hipóteses:

H1: Os investimentos sociais internos (ISI) influenciam positivamente o desempenho financeiro das empresas.

H2: Os investimentos sociais externos (ISE) influenciam positivamente o desempenho financeiro das empresas.

H3: Os investimentos ambientais (IA) influenciam positivamente o desempenho financeiro das empresas. 


\subsection{Estudos empíricos anteriores}

Quanto à temática da relação entre investimentos socioambientais e desempenho financeiro, foram identificados diversos estudos internacionais e nacionais. A revisão da literatura dos estudos é apresentada na Tabela 2, na qual é evidenciado o ambiente da pesquisa, os principais indicadores socioambientais e econômicos e uma síntese do resultado de tal relação.

Tabela 2 - Estudos sobre a relação entre investimentos socioambientais e desempenho financeiro

\begin{tabular}{|c|c|c|}
\hline Autores (ano) & $\begin{array}{c}\text { Proxy(ies) } \\
\text { socioambientais }\end{array}$ & $\begin{array}{c}\text { Proxy(ies) } \\
\text { financeiras }\end{array}$ \\
\hline Tupy (2008) & $\begin{array}{lr}\text { Investimentos em } \\
\text { meio ambiente } \mathrm{e} \\
\text { responsabilidade } \\
\text { social (IMARS) }\end{array}$ & $\begin{array}{l}\text { Mercado das } \\
\text { empresas (VM), } \\
\text { Lucro líquido (LL), } \\
\text { Patrimônio líquido } \\
\text { (PL), Endividamento } \\
\text { (E), Ativo total }\end{array}$ \\
\hline Campos (2011) & $\begin{array}{l}\text { Indicadores Sociais } \\
\text { Internos, Indicadores } \\
\text { Sociais Externos e } \\
\text { Indicadores } \\
\text { Ambientais }\end{array}$ & $\begin{array}{l}\text { Valor adicionado } \\
\text { pela empresa no ano } \\
\text { e folha Bruta per } \\
\text { capita }\end{array}$ \\
\hline $\begin{array}{c}\text { Orellano e } \\
\text { Quiota (2011) }\end{array}$ & $\begin{array}{l}\text { Indicadores Sociais } \\
\text { Internos, Indicadores } \\
\text { Sociais Externos e } \\
\text { Indicadores } \\
\text { Ambientais }\end{array}$ & $\begin{array}{l}\text { ROA, ROE e } Q \text { de } \\
\text { Tobin }\end{array}$ \\
\hline $\begin{array}{l}\text { Saleh et al. } \\
\text { (2011) }\end{array}$ & $\begin{array}{l}\text { Relações com os } \\
\text { funcionários, } \\
\text { envolvimento com a } \\
\text { comunidade, } \\
\text { dimensão do produto e } \\
\text { dimensão ambiental. }\end{array}$ & $\mathrm{ROA}, \mathrm{R}_{i}$ e $Q$ ratio \\
\hline $\begin{array}{l}\text { Lima et al. } \\
\text { (2013) }\end{array}$ & $\begin{array}{l}\text { Indicadores Sociais } \\
\text { Internos, Indicadores } \\
\text { Sociais Externos e } \\
\text { Indicadores } \\
\text { Ambientais }\end{array}$ & $\begin{array}{l}\text { Rendimento, Lucro } \\
\text { líquido, EBITDA e } \\
\text { Receita líquida. }\end{array}$ \\
\hline $\begin{array}{l}\text { Fasolin et al. } \\
\qquad(2014)\end{array}$ & $\begin{array}{l}\text { Check list das } \\
\text { Diretrizes para } \\
\text { Evidenciação } \\
\text { Ambiental e Social }\end{array}$ & $\begin{array}{l}\text { Diretrizes para } \\
\text { Evidenciação } \\
\text { Econômica } \\
\text { (Tamanho, } \\
\text { Rentabilidade } \\
\text { Endividamento) }\end{array}$ \\
\hline
\end{tabular}

Indicadores Sociais

Internos, Indicadores (2017)

Ambientais
Ribeiro et al.

\section{Indicadores}

As relações não foram estatisticamente significativas.

Resultado da relação

Existe uma relação positiva entre os indicadores sociais internos, incentivo remuneratório dos empregados atuantes nas empresas, contudo, não é observada pelos investimentos em meio ambiente efetuados pelas empresas pesquisadas.

Existe uma correlação positiva significativa entre o investimento social interno da empresa no ano em curso e os indicadores financeiros ROA e ROE do mesmo ano e do ano seguinte. Em relação as demais variáveis de desempenho socioambiental, não foram encontrados resultados claros.

Os resultados das estimativas indicam que há uma relação positiva e significativa da responsabilidade social corporativa no desempenho financeiro, também revelam que há evidências limitadas dessa relação no longo prazo.

Os investimentos socioambientais internos influenciam positivamente os indicadores econômico-financeiros: lucro líquido, EBITDA e receita líquida. Não foi encontrada nenhuma relação estatisticamente significativa com os demais indicadores.

Existe uma correlação positiva e significativa entre o índice de evidenciação da sustentabilidade com a variável independente tamanho. Quanto ao índice de evidenciação ambiental, o modelo de explicação é pouco representativo, pois as variáveis independentes são responsáveis apenas por $33,20 \%$.

De acordo com os resultados da pesquisa, os indicadores ROA e ROE apresentam resultados semelhantes em comparação com o investimento socioambiental e o porte da empresa. Em suma, o ISI tem uma relação positiva e significativa com os resultados do negócio. Porém, para o ISE, essa relação é negativa. Em termos de investimento ambiental, estes não têm impacto significativo no desempenho financeiro da empresa.

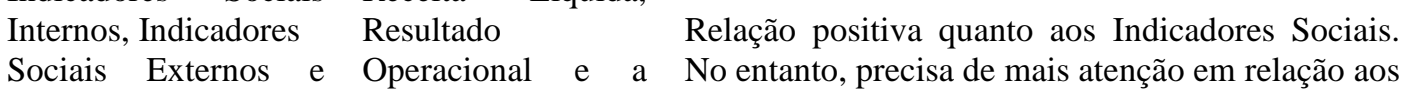

Goulart e Ferreira (2019) Indicadores Ambientais Bruta
Folha de Pagamento 


\begin{tabular}{|c|c|c|c|}
\hline $\begin{array}{l}\text { Paiva et al. } \\
\text { (2019) }\end{array}$ & $\begin{array}{l}\text { Indicadores Sociais e } \\
\text { Ambientais }\end{array}$ & $\begin{array}{l}\text { Crescimento } \\
\text { Médio Anual }\end{array}$ & $\begin{array}{l}\text { Os resultados evidenciaram as práticas de } \\
\text { responsabilidade socioambiental e a associação } \\
\text { positiva entre essas e o desempenho econômico } \\
\text { das pequenas e médias empresas que mais crescem } \\
\text { no Brasil. }\end{array}$ \\
\hline $\begin{array}{l}\text { Círico Junior e } \\
\text { Galvão (2020) }\end{array}$ & $\begin{array}{l}\text { Indicadores Sociais } \\
\text { Internos, Indicadores } \\
\text { Sociais Externos e } \\
\text { Indicadores } \\
\text { Ambientais }\end{array}$ & $\begin{array}{l}\text { Receita Líquida, } \\
\text { Resultado } \\
\text { Operacional e Folha } \\
\text { de pagamento bruta }\end{array}$ & $\begin{array}{l}\text { Neutra, para uma empresa tornar-se socialmente } \\
\text { responsável, necessita que haja mais investimentos } \\
\text { e interação com questões ambientais e sociais. }\end{array}$ \\
\hline $\begin{array}{l}\text { Partalidou et al. } \\
\qquad(2020)\end{array}$ & $\begin{array}{l}\text { Aspectos distintos do } \\
\text { conceito de RSA: } \\
\text { ambiental, social e } \\
\text { governança }\end{array}$ & $\begin{array}{l}\text { Lucro Operacional } \\
\text { e Pontuação } \\
\text { Econômica }\end{array}$ & $\begin{array}{l}\text { Os aspectos da responsabilidade social corporativa } \\
\text { afetam positivamente o desempenho financeiro. }\end{array}$ \\
\hline $\begin{array}{l}\text { Cruz et al. } \\
\quad(2020)\end{array}$ & $\begin{array}{l}\text { Indicadores Sociais e } \\
\text { Ambientais }\end{array}$ & $\begin{array}{l}\text { ROA, ROE e valor } \\
\text { adicionado sobre a } \\
\text { receita total }\end{array}$ & $\begin{array}{l}\text { Há uma relação negativa e estatisticamente } \\
\text { significativa entre o indicador ROA com os } \\
\text { indicadores da DVA (VAE, VAG e VAC). }\end{array}$ \\
\hline
\end{tabular}

Fonte: Elaborada pelos autores (2021).

Apesar da maioria dos estudos pesquisados anteriormente, tanto nacionais como internacionais, apontarem para a existência de relação positiva entre investimentos socioambientais e desempenho financeiro, não há ainda consenso acerca de tal relação, já que alguns resultados são neutros e outros negativos.

Ante a essa divergência de resultados, este estudo investiga a relação entre investimentos socioambientais e desempenho financeiro em um período de pós-obrigatoriedade da divulgação do Relatório de Responsabilidade Socioambiental pelo setor de energia elétrica, buscando assim verificar se houve mudanças nesta relação quando se há a obrigação da divulgação de tais informações. Esse é, portanto, o maior diferencial em relação a estudos anteriores que realizaram pesquisa semelhante.

\section{METODOLOGIA}

Esta pesquisa se caracteriza como sendo descritiva, pois, segundo Gil (2019) esse tipo de pesquisa possui como objetivo principal descrever o estabelecimento de relações existentes entre características ou variáveis de uma determinada população ou fenômeno. Assim sendo, o presente estudo busca, por meio da coleta de dados de um universo de empresas, investigar a relação entre os indicadores socioambientais e o desempenho financeiro. Para tanto, foram estudadas empresas listadas na Bovespa pertencentes ao segmento de energia elétrica de 2015 a 2019.

Quanto ao procedimento, fez-se o uso da pesquisa documental. Para Marconi e Lakatos (2019), a característica principal da pesquisa documental é a sua fonte de coleta de dados, sendo "restrita a documentos, escritos ou não, constituindo o que se denomina de fontes primárias" (p. 174). A pesquisa, quanto à abordagem ao problema, é quantitativa, já que é constituída de um processo sistêmico de coleta de dados que possam ser observados e quantificados (Freixo, 2011).

\subsection{Caracterização da amostra}

O universo da pesquisa é composto por 57 empresas de capital aberto listadas na B3 no segmento de energia elétrica. A escolha desse segmento se deu por sua relevância nos aspectos econômicos, sociais e ambientais, e por ser um setor regulado pela Aneel, a qual o obriga a realizar a divulgação do Relatório de Responsabilidade Socioambiental desde o ano de 2015. Além do mais, esse segmento, conforme Lima et al. (2013), possui elevado impacto ao meio ambiente e forte investimento socioambiental em ações de pesquisa e desenvolvimento e de eficiência energética que, porventura, impactam em mudanças nos aspectos econômicos, sociais e ambientais. 
A seleção da amostra se deu de forma não probabilística e por conveniência. Assim sendo, as empresas selecionadas estão restritas às empresas brasileiras que: possuem capital aberto; sejam do setor de energia elétrica; façam parte de algum segmento de Governança Corporativa do Índice Bovespa; e apresentem os dados que permitam a realização do cálculo dos indicadores socioambientais. A amostra final compreendeu quatorze empresas, conforme evidencia a Tabela 3.

Tabela 3 - Nominata das organizações que compõem a amostra da pesquisa

\begin{tabular}{ccc}
\hline Segmento & Empresa & Total por segmento \\
\hline & ALUPAR & \\
N2 (Nível 2 de Governança & CELESC & 4 \\
Corporativa) & ENERGISA & \\
& TAESA & \\
& CEEE-D & \\
N1 (Nível 1 de Governança & CEEE-GT & \\
Corporativa) & CEMIG & \\
& CESP & \\
& COPEL & \\
NM (Novo Mercado) & ELETROBRAS & \\
& ENERGIAS BR & 14 \\
\hline
\end{tabular}

Fonte: Elaborada pelos autores (2021).

Observa-se, com base na Tabela 3, que a maior parte das empresas (seis) faz parte do segmento N1. Os segmentos $\mathrm{N} 2$ e NM possuem 4 empresas, respectivamente. Atualmente a Bovespa possui 5 segmentos especiais de listagem - Bovespa Mais, Bovespa Mais Nível 2, Novo Mercado, Nível 2 e Nível 1. Há ainda o Segmento Básico, segmento de listagem da Bovespa que não possui regras diferenciadas de governança corporativa $\left(\mathrm{B}^{3}, 2020\right)$.

Assim como na pesquisa de Ribeiro et al. (2017), nesta pesquisa os dados foram coletados de duas maneiras distintas.

1. Dados socioambientais: Para identificar os dados socioambientais, são utilizadas as informações contidas no balanço social, para que variáveis independentes possam ser construídas.

2. Dados financeiros: Para se obter os dados necessários para o cálculo das varáveis de desempenho financeiro e de controle, foram utilizadas as informações disponibilizadas no website da Bovespa.

\subsection{Variáveis da pesquisa}

A seleção das variáveis teve como parâmetro o atingimento do objetivo proposto nesta pesquisa. De acordo com Gil (2019), as variáveis podem ser definidas como tudo aquilo que possa assumir diferentes valores numéricos, mas, em termos de pesquisa, pode-se entender como qualquer coisa capaz de ser classificada em duas ou mais categorias. As variáveis no presente estudo referem-se a constructos que buscam analisar a relação entre os investimentos socioambientais e desempenho financeiro, tendo o tamanho como variável de controle, conforme destacado na Tabela 4. 
Mota, J. dos S. O., \& Pimentel, M. S. (2021). A Relação entre Investimentos Socioambientais e Desempenho Financeiro: Evidências do Setor Energético Brasileiro

Tabela 4 - Variáveis da pesquisa

\begin{tabular}{|c|c|c|c|c|}
\hline Categoria & Variável & \multicolumn{2}{|l|}{ Configuração } & Fonte Empírica \\
\hline \multicolumn{5}{|c|}{ Variável dependente } \\
\hline \multirow{2}{*}{$\begin{array}{l}\text { Desempenho } \\
\text { financeiro }\end{array}$} & ROA & \multicolumn{2}{|c|}{$\begin{array}{l}\text { Considera a razão entre o lucro líquido e o total de ativos da } \\
\text { companhia. }\end{array}$} & $\begin{array}{l}\text { Orellano e Quiota } \\
(2011) \text { e Ribeiro et } \\
\text { al. (2017) }\end{array}$ \\
\hline & ROE & \multicolumn{2}{|c|}{$\begin{array}{l}\text { Obtido pela divisão entre o lucro líquido e o total de } \\
\text { patrimônio líquido da Empresa. }\end{array}$} & $\begin{array}{l}\text { Orellano e Quiota } \\
(2011) \text { e Ribeiro et } \\
\text { al. (2017) }\end{array}$ \\
\hline Categoria & Variável & Fórmula & $\begin{array}{c}\text { Relação } \\
\text { Aguardada }\end{array}$ & Fonte Empírica \\
\hline \multicolumn{5}{|c|}{ Variáveis independentes } \\
\hline $\begin{array}{l}\text { Indicador Social } \\
\text { Interno }\end{array}$ & ISI & $\begin{array}{l}\text { Representa a razão entre os encargos } \\
\text { sociais compulsórios e os demais } \\
\text { benefícios ou encargos sociais } \\
\text { concedidos aos funcionários e o total de } \\
\text { ativos da companhia. }\end{array}$ & Positiva & $\begin{array}{l}\text { Torres e Mansur } \\
(2011) \text { Orellano e } \\
\text { Quiota (2008) e } \\
\text { Ribeiro et al. (2017) }\end{array}$ \\
\hline $\begin{array}{l}\text { Indicador Social } \\
\text { Externo }\end{array}$ & ISE & $\begin{array}{l}\text { Representa a } \text { razão entre os } \\
\text { investimentos } \\
\text { poluntários realizado } \\
\text { pelas empresas para as comunidades } \\
\text { externas e o total de ativos da } \\
\text { companhia. }\end{array}$ & Positiva & $\begin{array}{l}\text { Torres e Mansur } \\
(2008) \text { Orellano e } \\
\text { Quiota (2011) e } \\
\text { Ribeiro et al. }(2017)\end{array}$ \\
\hline $\begin{array}{l}\text { Indicador } \\
\text { Ambiental }\end{array}$ & IA & $\begin{array}{l}\text { Representa a razão entre os gastos } \\
\text { empresariais em ações que visam } \\
\text { mitigar os problemas ambientais e o } \\
\text { total de ativos da companhia. }\end{array}$ & Positiva & $\begin{array}{l}\text { Torres e Mansur } \\
(2008) \text { Orellano e } \\
\text { Quiota (2011) e } \\
\text { Ribeiro et al. (2017) } \\
\end{array}$ \\
\hline Controle & $\begin{array}{l}\text { Tamanho } \\
\text { (TAM) }\end{array}$ & $\begin{array}{l}\text { Representa os totais de ativos da } \\
\text { empresa em cada período. }\end{array}$ & Positiva & Ribeiro et al. (2017) \\
\hline
\end{tabular}

Fonte: adaptado de Torres e Mansur (2008), Orellano e Quiota (2011) e Ribeiro et al. (2017).

Após a obtenção das variáveis necessárias, três modalidades de análise foram adotadas: análise descritiva, análise de correlação e análise de regressão com dados em painel, realizadas por meio do software IBM SPSS Statistics 25.0 e Gretl 2021a.

\section{RESULTADOS E DISCUSSÕES}

Os resultados obtidos evidenciam que, em relação aos indicadores de desempenho financeiro, o retorno sobre os ativos demonstra, em média, 3\% de percentual e $14 \%$ de retorno sobre o Patrimônio Líquido, resultado parecido com o de Ribeiro et al. (2017), no qual os percentuais foram de 5\% para o ROA e $14 \%$ para o ROE.

Tabela 5 - Análise descritiva

\begin{tabular}{l|c|c|c|c}
\hline Variáveis & Média & Erro Desvio & Mínimo & Máximo \\
\hline ROA & 0,03 & 0,07 & $-0,26$ & 0,22 \\
\hline ROE & 0,14 & 0,17 & $-0,36$ & 1,06 \\
\hline ISI & 515674,40 & 773687,61 & 27172,00 & 3485286,00 \\
\hline ISE & 93367,44 & 170951,41 & 8,00 & 951880,00 \\
\hline IA & 183046,59 & 267988,51 & 530,00 & 1038684,00 \\
\hline TAM $^{*}$ & 30572750,50 & 41449798,36 & 2918824,00 & 181210208,00 \\
\hline
\end{tabular}

Nota: *Milhares de reais.

Fonte: Elaborada pelos autores (2021). 
Quanto aos investimentos socioambientais, têm-se que, em média, as empresas destinaram $\mathrm{R} \$ 515.674,40$ para benefícios ou encargos sociais concedidos aos funcionários - investimentos sociais internos, sendo esses os maiores montantes de recursos aplicados. Os investimentos sociais externos representam, em média, $\mathrm{R} \$ 93.367,44$ por empresa. Já os investimentos ambientais correspondem a $\mathrm{R} \$ 183.046,59$. Diferentemente desses achados, Lima et al. (2013) verificaram que a maior concentração dos investimentos socioambientais ocorreu nos indicadores externos.

Por fim, o tamanho das empresas, indicada pela variável TAM, tem valores médios em torno de R \$ 30 bilhões para os ativos. Assim como no trabalho de Ribeiro et al. (2017), no qual a Eletrobras se destacou com o maior montante de ativos, nesta pesquisa seu montante foi de aproximadamente R\$ 181 bilhões. Nota-se que, de maneira geral, os valores médios dos investimentos socioambientais são relativamente expressivos. No entanto, quando comparados com o patrimônio das empresas, tornam-se baixos em termos percentuais.

Dando sequência, tem-se a análise de correlação, evidenciada na Tabela 6 , por meio da qual se observa a existência de uma relação negativa (inversa) e significativa ( $p$-value $>0,01)$ entre as variáveis ISI e ROA, indicando, a priori, que quanto menor for o valor do retorno dos ativos das empresas, maior serão os investimentos sociais. É possível observar, também, a presença de relação positiva e significativa ( $p$-value $>0,01)$ entre ROE e ROA, o que sugere que empresas com maior retorno sobre os ativos tendem ainda a ter maior retorno do patrimônio líquido.

Tabela 6 - Análise de correlação

\begin{tabular}{|c|c|c|c|c|c|c|c|}
\hline Variáveis & Testes & ROA & ROE & ISI & ISE & IA & TAM \\
\hline \multirow{2}{*}{ ROA } & Pearson & \multirow{2}{*}{1} & - & - & - & - & - \\
\hline & Spearman & & - & - & - & - & - \\
\hline \multirow{2}{*}{ ROE } & Pearson & $-0,083$ & \multirow{2}{*}{1} & - & - & - & - \\
\hline & Spearman & $0,614^{* *}$ & & - & - & - & - \\
\hline \multirow{2}{*}{ ISI } & Pearson & $-0,625^{* *}$ & $0,289^{*}$ & \multirow{2}{*}{1} & - & - & - \\
\hline & Spearman & $-0,445^{* *}$ & $-0,034$ & & - & - & - \\
\hline \multirow{2}{*}{ ISE } & Pearson & $-0,064$ & $-0,186$ & 0,030 & \multirow{2}{*}{1} & - & - \\
\hline & Spearman & $-0,305^{*}$ & $-0,480^{* *}$ & $-0,084$ & & - & - \\
\hline \multirow{2}{*}{ IA } & Pearson & $-0,022$ & $-0,127$ & 0,013 & $0,289^{*}$ & \multirow{2}{*}{1} & - \\
\hline & Spearman & $-0,462^{* *}$ & $-0,377^{* *}$ & $0,297^{*}$ & $0,496^{* *}$ & & - \\
\hline \multirow{2}{*}{ TAM } & Pearson & $-0,013$ & $-0,243^{*}$ & $-0,114$ & $-0,091$ & $-0,080$ & \multirow{2}{*}{1} \\
\hline & Spearman & 0,028 & $-0,212$ & $-0,151$ & 0,163 & 0,177 & \\
\hline
\end{tabular}

Nota: *. A correlação é significativa no nível $0,05 .{ }^{* *}$. A correlação é significativa no nível 0,01.

Fonte: Elaborada pelos autores (2021).

Os achados da correlação se assemelham aos de Ceretta et al. (2009), entre os quais não constatou correlação entre os indicadores sociais internos, externos e ambientais, o que atendeu às exigências dos modelos. No entanto, divergem dos resultados de Soares et al. (2010) e de Lima et al. (2013), uma vez que esses aduziram para a presença de correlação entre os indicadores socioambientais e o desempenho das empresas e com os de Souza et al. (2016) que evidenciaram correlação entre os investimentos ambientais com as variáveis de desempenho econômico. Em síntese, corroboram com os estudos de Orellano e Quiota (2011) e o de Fasolin et al. (2014), apontando para a existência de relação entre investimento social interno e desempenho financeiro, em específico.

Por fim, realizou-se análise de regressão com dados em painel visando analisar o relacionamento entre o desempenho financeiro e os investimentos socioambientais das empresas. Para análise, inicialmente foi adotado o modelo Pooled (mínimos quadrados ordinários - MQO). Nesse modelo, assim como no estudo de Ribeiro et al. (2017), ISI, ISE e IA são usados como variáveis explicativas, e os indicadores de rentabilidade ROA e ROE são selecionados como variáveis dependentes. 
Com base nos resultados, foi realizado um painel de diagnóstico e observado o modelo que melhor explicava os objetivos da pesquisa. Primeiro, utilizou-se o teste de Chow para verificar se o modelo Pooled era o mais apropriado. No teste, rejeitar H0 significa que o modelo de efeitos fixos seria o mais conveniente. $\mathrm{O}$ segundo teste utilizado foi o teste de Breusch-Pagan, no qual a refutação $\mathrm{H} 0$ confirma que o modelo de efeitos aleatórios foi mais adequado do que o modelo Pooled. Finalmente, foi realizado o teste de Hausman, por meio do qual, ocorrendo a rejeição da hipótese nula, aduz-se que o modelo de efeitos aleatórios não foi adequado (Ribeiro et al., 2017).

Assim sendo, de acordo com esses parâmetros e resultados obtidos na Tabela 7 , referente à variável dependente ROA, tem-se que o modelo mais consistente é o de efeitos aleatórios. Doravante aos resultados, tem-se que os investimentos sociais internos apresentaram uma relação negativa e significativa $(\beta=-3,40854 ; \mathrm{p}<0,01)$ em relação ao retorno sobre os ativos, sugerindo que os investimentos realizados com os colaboradores refletiram negativamente no desempenho da empresa.

Tabela 7 - Análise de regressão para a variável ROA

\begin{tabular}{|c|c|c|c|}
\hline Variável dependente: & \multicolumn{3}{|c|}{ ROA } \\
\hline Período: & \multicolumn{3}{|c|}{$2015-2019$} \\
\hline Total de observações: & \multicolumn{3}{|c|}{70} \\
\hline \multirow{2}{*}{ Variáveis } & Modelo 1 - & Modelo 2 - & Modelo 3 - \\
\hline & Pooled & efeitos fixos & efeitos aleatórios \\
\hline Constante & $0,0959^{* * *}$ & 0,0642 & $0,0976^{* * * *}$ \\
\hline \multicolumn{4}{|l|}{ Variáveis independentes } \\
\hline ISI & $-3,11267^{* * *}$ & $-3,51133^{* *}$ & $-3,40854^{* * *}$ \\
\hline ISE & $-0,350428$ & $-0,429336$ & $-0,469040$ \\
\hline IA & $-0,0302987$ & $-0,153345$ & $-0,158079$ \\
\hline \multicolumn{4}{|l|}{ Variáveis de controle } \\
\hline Tamanho & $-1,59049 \mathrm{e}-010$ & $1,17 \mathrm{E}-09$ & $1,76 \mathrm{E}-11$ \\
\hline $\mathrm{R}$ - quadrado & 0,40096 & 0,785328 & - \\
\hline F de Fisher & 10,87674 & 11,19003 & - \\
\hline Akaike (CIA) & $-194,8095$ & $-240,6449$ & $-192,8406$ \\
\hline Schwarz (CIS) & $-183,5671$ & $-200,1720$ & $-181,5981$ \\
\hline \multirow{2}{*}{ Teste F } & 18,0443 & - & - \\
\hline & {$[0,0012]$} & - & - \\
\hline \multirow{2}{*}{ Teste de Breusch-Pagan } & 38,5217 & - & - \\
\hline & {$[0,0000]$} & - & - \\
\hline \multirow{2}{*}{ Teste de Hausman } & 2,95103 & - & - \\
\hline & {$[0,5660]$} & - & - \\
\hline
\end{tabular}

Nota: ${ }^{* *}$. A correlação é significativa no nível $0,05 .^{* * *}$. A correlação é significativa no nível 0,01 .

Fonte: Elaborada pelos autores (2021).

Nesse cenário, rejeitou-se a H1 da pesquisa que aduz que os ISI influenciam positivamente o desempenho financeiro das empresas. Os resultados são divergentes aos encontrados por Orellano e Quiota (2011) e Ribeiro et al. (2017), uma vez que nestes estudos a relação foi positiva e significativa entre o investimento social interno e o indicador de desempenho financeiro ROA.

Quanto aos investimentos sociais externos e os ambientais, averiguou-se uma relação negativa com o ROA. No entanto, não foi constatado significância estatística, não permitindo, portanto, que se confirme tais achados. Tem-se, assim, que para a variável ROA, rejeitou-se as $\mathrm{H} 2 \mathrm{e}$ H3, já que essas sugerem que os ISE e IA possuem relação positiva com o desempenho financeiro. Com relação a variável controle - TAM, foi constatada relação positiva, porém sem significância. 
Estes resultados, quando comparados com os de Orellano e Quiota (2011) e Ribeiro et al. (2017), também divergiram, no entanto, em ambas pesquisas os resultados não foram significativos. No estudo de Cruz et al. (2020), não houve relação estatística significante entre gastos ambientais e a variável dependente ROA. Em síntese, os resultados se assemelham aos de Lima et al. (2013), indicando que nenhum dos indicadores socioambientais influenciam positivamente o desempenho das empresas.

Na Tabela 8, são demostrados os resultados da análise de regressão com dados em painel para a variável dependente ROE. Com base nos parâmetros para o modelo mais consistente e nos resultados do diagnóstico em painel, tem-se que o modelo adotado foi o Pooled.

Diferentemente dos resultados obtidos para o ROA, os achados indicaram que os ISI apresentaram uma relação positiva e significativa $(\beta=3,01245$; $\mathrm{p}<0,05)$ com retorno sobre o PL. Esses resultados, assim como os de Orellano e Quiota (2011) e Ribeiro et al. (2017), enfatizam que investimentos realizados com colaboradores possui relação positiva com o retorno dos acionistas. Dessa forma, para variável ROE, não se rejeita a H1.

Tabela 8 - Análise de regressão para a variável ROE

\begin{tabular}{l|c|c|c}
\hline Variável dependente: & \multicolumn{3}{|c}{ ROE } \\
\hline Período: & \multicolumn{3}{|c}{$2015-2019$} \\
\hline \multirow{2}{*}{ Variáveis } & \multicolumn{3}{|c}{70} \\
\hline Constante observações: & Modelo 1 - & Modelo 2 - & Modelo 3 - \\
\cline { 2 - 4 } Variáveis independentes & Pooled & efeitos fixos & efeitos aleatórios \\
\hline ISI & $0,132278^{* * *}$ & 0,0664939 & $0,136748^{* * *}$ \\
\hline ISE & & & 2,11749 \\
\hline IA & $3,01245^{* *}$ & $-6,01941$ & $-1,90470$ \\
\hline Variáveis de controle & $-2,90709$ & $-1,07523$ & $-0,874508$ \\
\hline Tamanho & $-1,12135$ & $-0,382351$ & \\
\hline R - quadrado & & & $-7,39281 \mathrm{e}-010$ \\
\hline F de Fisher & $-9,49465 \mathrm{e}-010^{* *}$ & $6,41301 \mathrm{E}-09^{* * *}$ & \\
\hline Akaike (CIA) & 0,182553 & 0,546389 & $-56,45605$ \\
\hline Schwarz (CIS) & $3,628968^{* * *}$ & $3,684451^{* * *}$ & $-45,21357$ \\
\hline \multirow{2}{*}{ Teste F } & $-57,67824$ & $-72,90445$ & - \\
\hline \multirow{2}{*}{ Teste de Breusch-Pagan } & $-46,43576$ & $-32,43154$ & - \\
\hline \multirow{2}{*}{ Teste de Hausman } & 4,93176 & - & - \\
\hline
\end{tabular}

Nota: ${ }^{* *}$. A correlação é significativa no nível $0,05{ }^{* * *}$. A correlação é significativa no nível 0,01.

Fonte: Elaborada pelos autores (2021).

Em sentido oposto a este resultado, tem-se novamente que as variáveis ISE e IA possuíram relação negativa com o retorno sobre o PL. Ambas variáveis não possuíram significância, não permitindo que se confirmem tais resultados. Os achados foram contrários aos de Orellano e Quiota (2011), pois, em seus estudos, a relação entre esses indicadores foi positiva, porém também sem significância. Com isso, para as duas variáveis de desempenho, ROA e ROE, se rejeitou as H2 e H3 deste estudo.

Ressalta-se que a variável TAM impactou negativamente o ROE, o que sugere que a relação entre os investimentos socioambientais e o desempenho, em empresas menores, foi manifestada de forma mais perceptível. 
Por meio do Tabela 9, são apresentados os resultados dos testes de hipótese a despeito da relação entre os indicadores socioambientais e as variáveis relativas ao desempenho financeiro das empresas.

Tabela 9 - Resumo dos testes de hipóteses

\begin{tabular}{cccc}
\hline \multicolumn{2}{c}{ ROA } & \multicolumn{2}{c}{ ROE } \\
\hline H1 & Rejeita & H1 & Não rejeita \\
\hline H3 & Rejeita & H2 & Rejeita \\
\hline & Rejeita & H3 & Rejeita \\
\hline
\end{tabular}

Fonte: Elaborada pelos autores (2021)

Assim sendo, os achados em relação a H1 têm-se uma rejeição parcial, pois os ISI não influenciam positivamente o desempenho financeiro quando se trata do retorno sobre os Ativos (ROA). No entanto, os ISI influenciam positivamente o desempenho financeiro das empresas, ao tratar do retorno sobre o patrimônio líquido. Quanto às hipóteses H2 (os ISE influenciam positivamente o desempenho financeiro) e H3 (os IA influenciam positivamente o desempenho financeiro), foram rejeitadas, pois os resultados sugerem que os investimentos em tais áreas, pelas empresas do setor de energia elétrica, não impactam positivamente o desempenho financeiro de forma significativa.

Tais resultados assemelham-se com os achados de Orellano e Quiota (2011) e de Ribeiro et al. (2017) no que se refere à rejeição da relação entre as variáveis ISE e IA com o desempenho financeiro das empresas e, de forma parcial, no impacto positivo dos ISI no desempenho financeiro das companhias. Corroboram com os de Tupy (2008) que evidenciaram não haver relações estatisticamente significativas entre investimentos socioambientais e indicadores de desempenho financeiro, em termos de proporções do ativo e do patrimônio líquido das empresas, excetuando a relação entre ISI e ROE. O estudo de Campos (2011) também evidencia que os investimentos ambientais não possuem relação significativa com o desempenho de uma organização. Diferentemente, os resultados apresentados por Pletsch et al. (2015) enfatizaram que existe relação entre o desempenho financeiro e os investimentos sociais internos e externos, isto é um maior desempenho impacta em maiores investimentos sociais.

\section{CONSIDERAÇÕES FINAIS}

Esta pesquisa objetivou analisar a relação entre os investimentos em práticas socioambientais e o desempenho financeiro das empresas de capital aberto do segmento de energia elétrica que publicaram seus Relatórios Socioambientais entre os anos de 2015 e 2019 . Utilizou-se da análise de regressão com dados em painel como mecanismo de resposta ao objetivo proposto. $\mathrm{Na}$ análise, as variáveis ISI, ISE e IA foram usadas como sendo independentes, seguindo como parâmetro o modelo Ibase. Como proxis do desempenho financeiro das empresas, foram utilizados os indicadores ROA e ROE. Como variável de controle, empregou-se o TAM - total do ativo de cada empresa.

Com base nos resultados do estudo, os indicadores ROA e ROE obtiveram resultados semelhantes em comparação com os investimentos socioambientais e o porte das companhias, com exceção da variável ISI. Em suma, o ISI demonstrou uma relação parcial com os resultados do negócio, mostrando que o investimento nos colaboradores tem gerado retorno positivo para os acionistas da empresa, não sendo observado para o retorno dos ativos, que teve relação negativa e significativa. Com relação aos investimentos externos e ambientais, não afetaram significativamente o desempenho financeiro da empresa.

Observou-se que, mesmo após um período de pós-obrigatoriedade da divulgação das informações socioambientais, os resultados continuam semelhantes aos evidenciados no estudo de Ribeiro et al. (2017). Assim sendo, o ato de somente evidenciar não implica que haverá uma relação de causa e efeito entre investimentos socioambientais e o desempenho financeiro das empresas, faz- 
se necessário que ocorram maiores investimentos, principalmente em recursos externos e ambientais para que potencialize esta relação.

Os achados evidenciam que, de maneira geral, os valores médios dos investimentos socioambientais são relativamente expressivos. Contudo, em relação ao patrimônio das empresas se tornam baixos em termos percentuais. O que corrobora com a necessidade de maiores investimentos socioambientais, uma vez que os ISI - os mais expressivos, possuem relação positiva com o patrimônio líquido. Cita-se ainda que estes investimentos gerarão benefícios, visto que é parcialmente mencionado, que a responsabilidade social melhora a boa vontade do funcionário, juntamente com a moral e a produtividade.

A principal contribuição deste trabalho está relacionada aos investimentos em práticas socioambientais, em especial, investimentos sociais internos, proporcionarem ganhos financeiros aos acionistas, ou seja, investir em políticas de treinamento e estimular seu quadro de colaboradores apresentou retorno econômico positivo. Isso se coaduna com os ODS, à medida que as empresas do segmento de energia elétrica são descritas como fundamentais para o desenvolvimento dos países, seja em aspectos econômicos, financeiros, ambientais e sociais. Esse é um dos principais objetivos definidos na Agenda 2030 para o Desenvolvimento Sustentável (Objetivo 7), pela Organização das Nações Unidas (ONU), junto com a necessidade de uma gestão sustentável e um uso eficiente dos recursos naturais (Objetivo 12) (ONU, 2020).

Ressalta-se que os resultados obtidos se limitam às empresas que compõem a amostra deste estudo, uma vez que nem todas as empresas do universo estudado possuem dados suficientes para a realização do cálculo dos indicadores socioambientais. As limitações também estão relacionadas aos indicadores selecionados, ao período de amostragem e a exatidão das informações disponibilizadas no site da B3. Como recomendação para trabalhos futuros, sugere-se a utilização de outros segmentos da B3, com o intuito de realizar uma comparação entre tais segmentos no que concerne a relação entre os investimentos socioambientais e o desempenho financeiro das empresas.

\section{REFERÊNCIAS}

Abbott, W. F., \& Monsen, R. J. (1979). On the measurement of corporate social responsibility: selfreported disclosures as a method of measuring corporate social involvement. The Academy of Management Journal, 22(3), 501- 515. DOI: https://doi.org/10.2307/255740

Barnett, M. L., \& Salomon, R. M. (2006). Beyond Dichotomy: The Curvilinear Relationship between Social Responsibility and Financial Performance. Strategic Management Journal, 27(11), 1101-1122. DOI: https://ssrn.com/abstract=885950

Brasil. Agência Nacional de Energia Elétrica. (2001). Resolução no 444, de 26 de outubro de 2001. Institui o Manual de Contabilidade do Serviço Público de Energia Elétrica, englobando o Plano de Contas revisado, com instruções contábeis e roteiro para elaboração e divulgação de informações econômicas e financeiras. Diário Oficial da União, Brasília, DF. Recuperado em 20 de novembro de 2020 de http://bit.ly/2uG9abG

Brasil. Manual de Contabilidade do Setor Elétrico. 2015. Recuperado em 20 novembro de 2020 de https://www.aneel.gov.br/arquivos/PDF/MCSE_-_Versao_2015.pdf.

Brasil, Bolsa e Balcão - B³. (2020). Segmentos de listagem. Recuperado em 05 de janeiro de 2020 de http://www.b3.com.br/pt_br/produtos-e-servicos/solucoes-para-emissores/segmentos-delistagem/sobre-segmentos-de-listagem/

Carroll, A. B. (1979). A three-dimensional conceptual model of corporate performance. Academy of Management Review, 4(4), 497-505. DOI: https://www.jstor.org/stable/257850 
Ceretta, P. S., Vieira, K. M., Fonseca, J. L. da, \& Trindade, L. de L. (2009). Determinants of capital structure: an analysis of ibovespa enterprises from 1995 to 2007 . REGE Revista De Gestão, 16(4), 29-43. DOI: https://doi.org/10.5700/issn.2177-8736.rege.2009.36684

Círico Junior, A., \& Galvão, C. R. (2020). Responsabilidade Social Empresarial: estudo sob a ótica do desempenho empresarial passado por meio da análise dos indicadores sociais e ambientais de uma empresa do setor de papel e celulose. Exacta, 18(2), 334-354. DOI: https://doi.org/10.5585/exactaep.v18n2.8820

Cohen, M., Cavazotte, F. de S. C. N., Costa, T. M. da, \& Ferreira, K. C. S. (2017). Corporate Social-Environmental Responsibility as an Attraction and Retention Factor for Young Professionals. Brazilian Business Review, 14(1), 21-41. DOI: https://doi.org/10.15728/bbr.2017.14.1.2

Cochran, P. L., \& Wood, R. A. (1984). Corporate social responsibility and financial performance. The Academy of Management Journal, 27(1), 42-56. DOI: https://doi.org/10.1002/csr.1781

Cruz, W. H., Miranda, G. J., \& Ribeiro, R. B. (2020). Relação Entre Indicadores Socioambientais e Rentabilidade das Empresas Listadas na B3. Pensar Contábil, 22(78), 31-42.

Disegni, D. M., Huly, M., \& Akron, S. (2015). Corporate social responsibility, environmental leadership and financial performance. Social Responsibility Journal, 11(1), 131-148. DOI: https://doi.org/10.1108/SRJ-02-2013-0024

Elkington, J. (1994). Towards the sustainable corporation: win-win-win business strategies for sustainable development. California Management Review, 36(2), 90-100. DOI: https://doi.org/10.2307/41165746

Fasolin, L. B., Kaveski, I. D. S., Chiarello, T. C., Marassi, R. B., \& Heinn, N. (2014). Relação entre o Índice de Sustentabilidade e os Indicadores Econômico-financeiros das empresas de energia brasileiras. Revista Eletrônica em Gestão, Educação e Tecnologia Ambiental - REGET, 18(2), 955981. DOI: https://doi.org/10.5902/2236117013793

Fatemi, A., Glaum, M., \& Kaiser, S. (2018). ESG performance and firm value: the moderating role of disclosure. Global Finance Journal, 38, 45-64. DOI: https://doi.org/10.1016/j.gfj.2017.03.001

Faur, A. R., Machado, V. S., Fernandes, L. P., Monteiro, P. R. A., \& Ferreira, A. C. D. S. (2008). Balanço social relatório de desempenho social? Análise dos setores petroquímico e elétrico no Rio de Janeiro. Pensar Contábil, 6(25).

Freixo, M. (2011). Metodologia cientifica: fundamentos, métodos e técnicas. Lisboa: Instituto Piaget.

Gil, A. C. (2019). Métodos e técnicas de pesquisa social. 7. ed. São Paulo: Atlas.

Goulart, L. T., \& Ferreira, D. D. M. (2019). Indicadores de Desempenho Socioambientais: uma análise no Balanço Social do Grupo Energisa nos anos de 2008 a 2017. XIII Congresso ANPCONT. Anais... São Paulo: ANPCONT.

Gri. Global Reporting Iniciative. Relatórios de Sustentabilidade da GRI: quanto vale essa jornada?. 2012. Recuperado em 28 dezembro de 2020 de https://silo.tips/download/relatorios-desustentabilidade-da-gri

Holme, R., \& Watts, P. (2000). Corporate social responsibility: making good business sense. Conches-Geneva: World Business Council for Sustainable Development. 
Irigaray, H. A. R., Vergara, S. C., \& Araujo, R. G. (2017). Responsabilidade Social Corporativa: o que revelam os relatórios sociais das empresas. Revista Organização \& Sociedade, 24(80), 73-88. DOI: https://doi.org/10.1590/1984-9230804

Jaber, T. (2020). A Surge toward a Sustainable Future: Organizational Change and Transformational Vision by an Oil and Gas Company. Revista de Administração Contemporânea, 25(3), e200031. DOI: https://doi.org/10.1590/1982-7849rac2021200031.en

Leinig, A. K. G., Pinto, J. S. P., Catapan, A., Catapan, E. A., Veiga, C. P., Panucci-Filho, L., Verona, L. A., Bueno, P.V., Costa Junior, E. V., Castro, A., Deretti, S. (2014). Electronic Reverse Auction: AnAnalysisof Its Use in Public Administrations of Cities in Brazil. Australian Journalof Basic and Applied Sciences, 8(13): 274-281. Recuperado em 15 de dezembro de 2020 de http://www.ajbasweb.com/old/ajbas/2014/August/274-281.pdf

Lima, A. A. P., Mello, L. C. O., Pessoa, M. N. M., Cabral, A. C. A., Rebouças, S. M. D. P., \& Santos, S. M. S. (2013). Investimentos socioambientais e o desempenho econômico-financeiro das empresas: estudo empírico nas companhias abertas listadas na BM\&FBovespa no Setor de Energia Elétrica. In: Congresso Brasileiro de Custos, 20. ,Uberlândia: CBC.

Lima, A. M. B., \& Santos, J. J. A. (2019). Responsabilidade Social: um estudo sobre o entendimento dos Contadores do Município de Jaguaretama quanto a Responsabilidade Social. Id on Line Rev. Mult. Psic., 13(48), 545-560. DOI: https://doi.org/10.14295/idonline.v13i48.2169

Marconi, M. de A., \& Lakatos, E. M. (2019). Fundamentos de metodologia científica. 8. ed. São Paulo: Atlas.

Campos, G. M. (2011). O impacto de indicadores socioambientais no valor adicionado por empresas. Enfoque: Reflexão Contábil, $30(1), \quad$ 83-93. $\quad$ DOI: https://doi.org/10.4025/enfoque.v30i1.11280

Onu. Organização das Nações Unidas. Sobre o nosso trabalho para alcançar os Objetivos de Desenvolvimento Sustentável no Brasil. Recuperado em 16 de dezembro de 2020 de https://brasil.un.org/pt-br/sdgs

Orellano, V. I. F., \& Quiota, S. (2011). Análise do retorno dos investimentos socioambientais das empresas brasileiras. Revista de Administração de Empresas, 51(5), 471-484. DOI: https://doi.org/10.1590/S0034-75902011000500005

Paiva, L. E. B., Araujo, F. J. A., Luca, M. M. M., \& Vasconcelos, A. C. (2019). Práticas de Responsabilidade Socioambiental e o Desempenho em Pequenas e Médias Empresas Brasileiras. Gestão \& Regionalidade, 35(106), 86-107. DOI: https://doi.org/10.13037/gr.vol35n106.5184

Partalidou, X., Zafeiriou, E., Giannarakis, G., \& Sariannidis, N. (2020). The effect of corporate social responsibility performance on financial performance: the case of food industry. Benchmarking: An International Journal, 27(10), 2701-2720. DOI: https://doi.org/10.1108/BIJ-112019-0501

Pletsch, C. S., Silva, A., \& Hein, N. (2015). Responsabilidade Social e Desempenho EconômicoFinanceiro das Empresas Listadas no Índice de Sustentabilidade Empresarial - ISE. Revista de Gestão Social e Ambiental, 9(2), 53-69. DOI: https://doi.org/10.5773/rgsa.v9i2.1018

Ribeiro, F., Alves, T. A., Taffarel, M., \& Menon, G. (2017). Responsabilidade Social Corporativa e o Desempenho Financeiro no setor de Energia Elétrica: um estudo com modelo de dados em painéis. Gestão \& Regionalidade, 33(99), 39-54. DOI: https://doi.org/10.13037/gr.vol33n99.3987 
Saleh, M., Zulkifli, N., \& Muhamad, R. (2011). Looking for evidence of the relationship between corporate social responsibility and corporate financial performance in an emerging Market. AsiaPacific Journal of Business Administration, 3(2), 165-190. DOI: https://doi.org/10.1108/17574321111169849

Soares, S. V., Lanzarin, J., \& Casagrande, M. D. H. (2010). Análise estatística do modelo IBASE de balanço social de uma empresa do setor de siderurgia. Enfoque: Reflexão Contábil, 29(2), 27-39. DOI: https://doi.org/10.4025/enfoque.v29i2.10861

Souza, T. R., Brighenti, J., \& Hein, N. (2016). Investimentos Ambientais e Desempenho Econômico-Financeiro das Empresas Brasileiras Listadas no Índice de Sustentabilidade Empresarial - ISE. Reuna, 21(2), 97-114.

Tinoco, J. E. P. (2010). Balanço Social e o relatório da Sustentabilidade. São Paulo: Atlas.

Tolmasquim, M. T. (Coord.). (2016). Energia renovável: hidráulica, biomassa, eólica, solar, oceânica. Rio de Janeiro: EPE.

Torres, C., \& Mansur, C. (2008). Balanço social, dez anos: o desafio da transparência. Rio de Janeiro: Ibase.

Tupy, O. (2008). Investimentos em meio ambiente, responsabilidade social e desempenho econômico-financeiro de empresas no Brasil. Revista de Estudos Politécnicos Polytechnical Studies Review, 6(10),73-86. Recuperado em 16 de novembro de 2020 de https://ainfo.cnptia.embrapa.br/digital/bitstream/item/40840/1/PROCIOT2008.00326.pdf

Waddock, S. A, \& Graves, S. B. (1997). The corporate social performance-financial performance link. Strategic Management Journal, 18(4), 303-319. DOI: https://www.jstor.org/stable/3088143

\section{O presente trabalho foi realizado com apoio da Coordenação de Aperfeiçoamento de Pessoal de Nível Superior - Brasil (CAPES) - Código de Financiamento 001.}

Mota, J. dos S. O., \& Pimentel, M. S. (2021). A Relação entre Investimentos Socioambientais e Desempenho Financeiro: Evidências do Setor Energético Brasileiro. Revista De Gestão Social E Ambiental, 15, e02736. https://doi.org/10.24857/rgsa.v15i2.2736 